\title{
Plano Plurianual com Densidade Macroestratégica na Gestão Pública Municipal: descri- ção e análise do processo de elaboração do PPA do município de Osasco (2018-2021)
}

\section{Pluriannual Plan (PPA) containing Macro-Strategic Density in Municipal Public Mana- gement: description and analysis of a PPA's elaboration process in the municipality of Osasco, Brazil (2018-2021)}

\author{
Ingrid Cristine Rodrigues Nascimento \\ Universidade de São Paulo - USP - Brasil \\ ingriid.cristine@gmail.com \\ ORCID: 0000-0002-2631-859X \\ Fernando de Souza Coelho \\ Universidade de São Paulo - USP - Brasil \\ fernandocoelho@usp.br \\ ORCID: 0000-0003-2803-0722
}

Antonio Roberto Bono Olenscki

Universidade Estadual Paulista - UNESP - Brasil aolenscki@fclar.unesp.br

ORCID: 0000-0002-3066-1024

\author{
Raphael Borella Pereira da Silva \\ Universidade de São Paulo - USP - Brasil \\ raphael.borella@gmail.com \\ ORCID: 0000-0002-3551-5843
}

Submetido em 28/10/2019; Aprovado em 15/11/2019.

\begin{abstract}
Resumo
Objetivo: a literatura nacional sobre planejamento estratégico no setor público tem mostrado como o instrumento do Plano Plurianual (PPA), nos governos locais, permanece - recorrentemente - a ser estruturado sob uma perspectiva tão somente técnico-orçamentária, ou meramente como obrigação normativo-legal, com poucas evidências de seu potencial uso estratégico na gestão pública municipal. 0 presente artigo joga luz nessa temática, lançando mão do conceito de densidade macroestratégica e aplicando-o ao estudo de caso da formulação do PPA 2018-2021 do município de Osasco-SP. Metodologia: trata-se de investigação de natureza exploratória que se utilizou do método de estudo de caso com a triangulação de dados/informações advindos de análise documental, de entrevistas semiestruturadas com informantes-chave e da observação participante do processo por um dos autores deste trabalho no ano de 2017. Resultado: o texto descreve como o município elaborou o planejamento governamental e analisa se tal processo correspondeu aos princípios de densidade macroestratégica, assinalando, como resultado, a caracterização de um PPA Estratégico. Contribuição: a contribuição do artigo para a literatura nacional é empírica, uma vez que identifica a elaboração de um PPA Estratégico na gestão pública municipal - algo atípico nas prefeituras do país.
\end{abstract}

Palavras-Chave: Planejamento governamental, PPA, estratégia, governo municipal.

\section{Abstract}

Goal: Brazilian literature on strategic planning in the public sector has shown how the Pluriannual Plan (PPA) instrument in local governments remains - recurrently - structured from a purely technical-budgetary perspective, or merely as a legal obligation, with little evidence of its potential strategic use in municipal public management. This article sheds light on this subject, considering and employing the concept of macro-strategic density and applying it to the case study of the 2018-2021 Pluriannual 
Plan's formulation in the municipality of Osasco, Brazil. Methodology: this is an exploratory research that used the case study method with the triangulation of data / information from document analysis, semi-structured interviews with key informants and participant observation (in 2017) of the process by one of the authors of this present study. Result: the article describes how the municipality prepared the government planning and analyzes whether this process corresponded to the principles of macrostrategic density, indicating, as a result, the characterization of a Strategic PPA. Contribution: the paper contributes to the national literature in na empirical sense, once it identifies the raise and development of a Strategic-oriented PPA in a local public management, something unusual in the country's municipalities.

Keywords: Government Planning, Pluriannual Plan, Strategy, Municipal Government.

\section{Introdução}

No âmbito do planejamento governamental brasileiro, o Plano Plurianual (PPA) foi previsto na Constituição Federal de 1988 para ser o instrumento que está à disposição dos gestores públicos para orientar a formulação e implementação de políticas públicas aderentes a um plano de governo. A institucionalização de tal instrumento, nos últimos 30 anos, ocorre pari passu com o movimento da New Public Management (NPM) - traduzida como Nova Gestão Pública no país - e que implica, sobretudo, uma orientação para resultados no setor público. No Brasil, a partir da década de 1990, assistimos ao questionamento do modelo burocrático e a uma tentativa do modelo gerencial no governo federal, e o PPA tornou-se, nesse processo, um dos instrumentos aventados para a gestão por resultados.

Na federação brasileira, os municípios, independentemente do porte, estão sujeitos às regras constitucionais - idênticas ou similares - que determinam a elaboração de seu plano plurianual por meio de estimação de receitas e definição dos recursos que devem ser aplicados considerando os aspectos fiscais estabelecidos pelas condicionalidades normativas, como ocorre na formulação do PPA federal e dos estados. Ao analisar a lógica de capacidades estatais nesse nível de governo, observa-se que, frequentemente, as prefeituras têm dificuldades em elaborar os seus instrumentos de planejamento governamental. Logo, o PPA, que requer per si um modelo de planejamento e gestão das ações orçamentárias na qual sua elaboração deve levar em consideração a complexidade, as peculiaridades e as necessidades de cada município, muitas vezes torna-se meramente uma peça (na linguagem jurídica) formal-procedimental, sem institucionalização como ferramenta gerencial (Azevedo \& Aquino, 2016; Silva, 2017).

Em linhas gerais, a formulação dos PPAs nos municípios pode ser compreendida por uma tipologia formada por três arquétipos: o PPA de Gabinete, o PPA Encomendado e o PPA Estratégico. Por um PPA de Gabinete entende-se a elaboração do plano por meio de um processo imediatista e insulado no alto escalão da burocracia local para construção do instrumento com ênfase no cumprimento normativoprocessual e com pouca atenção aos elementos diretivos condizentes com um planejamento estratégico. Neste caso, o PPA se organiza por um processo decisório rápido e superficial que envolve apenas as secretarias (ou departamentos) fazendárias e alguns dirigentes públicos da prefeitura, fazendo uso de informações contábil-financeiras que simplificam o planejamento governamental dentro da rotina do orçamento público.

O segundo padrão, denominado PPA Encomendado, se refere à elaboração do plano delegada a membros externos da gestão pública por meio da contratação de agências de serviço especializado; nos pequenos municípios, por exemplo, é comum o emprego de escritórios de contabilidade e empresas de consultoria/assessoria regional. Nessa situação, observa-se com frequência a replicação de programas para múltiplos municípios, como se cada qual dispusesse de contextos territoriais, demográficos e socioeconômicos semelhantes. Por conseguinte, a tarefa de planejar se torna, geralmente, um encargo e redunda em um documento de gaveta, sem diagnósticos ou avaliações que representem com fidedignidade a realidade local, tendendo, assim, como no caso anterior, a desprezar os alcances estratégico-diretivos e táticos de um governo que almeje dar substância à resolução de problemas e à prospecção de oportunidades. Existem, obviamente, exceções: alguns casos em que prefeituras municipais, sobretudo de cidades de grande porte, contratam empresas de consultoria para apoiar a elaboração de um PPA dentro de uma lógica de planejamento estratégico.

Já a terceira especificação, identificada como PPA Estratégico, contempla as orientações do planejamento estratégico governamental pela presença de algumas diretrizes como: planejamento de longo 
prazo em base territorial; integração entre plano e orçamento; formulação de programas com profundidade diagnóstica de problemas, oportunidades e alternativas; uso de instituições de participação social; e responsabilização por resultados e uso de ferramentas de monitoramento e avaliação, com a devida gestão estratégica do plano. Essas orientações não são levadas em conta, via de regra, quando se elabora um PPA de Gabinete (e na maioria dos casos de PPA Encomendado), visto que consolidar uma estratégia requer uma lógica de alinhamento político, uma forma de pactuar objetivos/metas e a coordenação de ações governamentais entre as diversas organizações envolvidas no processo de construção e aplicação do plano plurianual. Como asseveram Olenscki et al (2017):

"O PPA é, em tese, um produto estruturante de ações de governo, de alinhamento e sob exame multi-institucionais, o que, evidentemente, impõe dificuldades à formulação estratégica por não se referir exclusivamente a uma organização e sim a uma teia, no mais das vezes, complexa de organizações. Neste sentido, se refere a um planejamento macroestratégico, mais do que simplesmente estratégico, e que se encerra em ações programáticas táticas". (OLENSCKI et al., 2017, p. 6, grifo nosso)

No que concerne ao molde de um PPA Estratégico, uma vez que as capacidades técnico-administrativas dos municípios brasileiros para o planejamento são limitadas - principalmente os de médio e pequeno porte (Papi \& Demarco, 2018) -, é raro o seu uso/aplicação nos governos locais; por conseguinte, é escassa a sua descrição e análise na literatura nacional de planejamento governamental, e os poucos casos identificados são genuínos outliers. Considerando essa lacuna, justifica-se este trabalho que, à luz do conceito de densidade macroestratégica, descreve e analisa o processo de elaboração do PPA 2018-2021 do município de Osasco-SP.

De antemão, cabe elucidar a definição operacional de densidade macroestratégica adotada na pesquisa. Essencialmente, compreende-se tal conceito no plano plurianual como: (i) o grau com que os conteúdos do PPA se traduzem nas leis e execuções orçamentárias, os quais, também em caso de alterações, sejam explícitos/transparentes e justificados, e (ii) o nível com que o PPA apresenta subsídios estratégicos por meio de objetivos, justificativas, metas físicas e financeiras, bem como indicadores de gestão e políticas públicas consistentes e claras para as realidades institucionais e temáticas as quais ele pertença ou se refira. Sua utilização como abordagem analítico-metodológica, proposta por Olenscki et al (2017), envolve o exame de sete variáveis político-administrativas na formulação do plano plurianual, a saber: ação/nuance de governo, liderança e memória institucional, participação social e permeabilidade organizacional aos cidadãos, ciclo político-eleitoral, mensuração de necessidade e recursos, alternativas de recursos financeiros e mecanismos de gestão tático-operacional de projetos. Todas elas serão elucidadas na seção 4 deste artigo, uma vez que foram empregadas na análise do PPA (2018-2021) de Osasco-SP.

Como subprodutos do estudo de caso único realizado em Osasco-SP, o texto tanto descreve como o município elaborou o plano plurianual 2018-2021, desvelando suas etapas, como analisa se tal processo correspondeu à noção de densidade macroestratégica, supramencionada. A escolha desse município deveu-se ao fato de a localidade ter vivenciado uma experiência exitosa na gestão anterior, confirmada pela bibliografia especializada recente (GUERRA et al, 2016; ORTIZ \& MEDEIROS, 2017), de elaborar um PPA Estratégico com empoderamento político e embasamento técnico, conduzido pela Secretaria de Planejamento e Gestão (SEPLAG).

Destarte, o pressuposto do projeto de pesquisa do qual derivou este artigo era que o PPA 20182021, elaborado no primeiro semestre de 2017, mantivesse sua feição estratégica e seu adensamento político e técnico, tendo em vista que a equipe de trabalho da SEPLAG permaneceu na municipalidade, apesar da alternância de poder entre partidos políticos e de mandatário (prefeito) decorrente das eleições municipais de 2016. A investigação levada a cabo na Prefeitura de Osasco foi de natureza exploratória e utilizou-se de três técnicas de coleta de dados: a análise documental de leis e relatórios, a realização de entrevistas semiestruturadas com informantes-chave da SEPLAG e a observação direta do processo de elaboração do PPA por um dos autores deste trabalho no primeiro semestre de 2017.

Rematando esta introdução, vale mencionar que o artigo está estruturado, na sequência, em cinco seções. A seção 2, abaixo, apresenta uma breve revisão da literatura sobre planejamento governamental no Brasil, enfocando o instrumento do plano plurianual. A seção 3, por seu turno, descreve o processo de elaboração do PPA 2018-2021 de Osasco, visando a uma exposição didática de suas etapas. A seção 
4, cerne do trabalho, analisa a elaboração de tal plano com base nas variáveis que delineiam o conceito de densidade macroestrátegica. Por último, a seção 5 tece as considerações finais com a tríade: síntese dos achados e contribuições, limitações do estudo e proposta de agenda de pesquisa.

\section{Planejar é Preciso! Estratégia, Planejamento Governamental e Plano Plurianual}

Em diversos manuais de planejamento estratégico, um trecho da obra clássica escrita por Lewis Carrol, "Alice no País das Maravilhas", adaptada como filme, é amplamente citado. A passagem refere-se a um diálogo entre dois personagens do conto, Alice e o Gato:

"Alice: Podes dizer-me, por favor, qual caminho devo seguir para sair daqui?

Isso depende muito do lugar para onde queres ir - respondeu o gato.

Preocupa-me pouco aonde ir - disse Alice.

Nesse caso, pouco importa o caminho que sigas - replicou o gato."

Vários especialistas da comunidade acadêmica (e de práticas) de estratégia destacam esse excerto - pedagogicamente - como um adágio para as organizações, qual seja: não saber aonde se quer chegar torna todos os caminhos possíveis. Nesse contexto, o planejamento pode ser compreendido como uma forma de determinar um ponto (ou os pontos) a ser(em) alcançado(s), traçando formas de tomada de decisões conscientes e projetando maneiras de conduzir ações consistentes. E no setor público, as escolhas dos caminhos podem variar substancialmente, de tal sorte que alguns problemas ganham mais relevo que outros com base na agenda do governo, e mesmo quando os diagnósticos são similares os propósitos podem ser distintos.

Grosso modo, a função do planejamento governamental é eleger prioridades e organizar intervenções que partam de uma situação inicial - de necessidades, deficiências, problemas e/ou oportunidades - para uma situação objetiva com níveis mais elevados de satisfação de bem-estar em determinado período. Maciel (1989), no artigo A crise do planejamento brasileiro, já afirmava que o ato de planejar em governos significa a adoção de um procedimento político e técnico, contínuo e sistêmico, com vistas à tomada de decisões e o estabelecimento de rumos. Enfim, como sustenta Matus (2006) em sua teoria sobre o Planejamento Estratégico Situacional no Setor Público, há um cálculo tecnopolítico que precede e preside as ações.

Extrapolando a ideia desses autores e trazendo uma conotação a esses múltiplos elementos apontados, o planejamento é político porque envolve olhares e escolhas diversos em um processo seletivo e, portanto, sem neutralidade alguma; técnico porque pressupõe métodos organizativos a partir do que se destaca como alternativas em meio às escolhas políticas; contínuo porque requer avaliação, monitoramento, ajustes orçamentários e de financiamento/oportunidades e aprendizado, evitando-se uma separação rígida entre planejar e executar/controlar; e sistêmico porque exige a atenção, por vezes, multicêntrica ou mesmo transversal entre áreas e setores diversos da gestão pública.

Mintzberg et al. (2010) enunciam que a formulação de estratégia é um processo de planejamento, análise, cognificação e aprendizado, além de negociação e concessões entre indivíduos, grupos e coalizões em conflito de modo que as estratégias resultam em um processo controlado e consciente de planejamento formal, decomposto em etapas distintas, cada uma delineada por checklists e apoiada por técnicas. Dentro do que convencionaram chamar de Escola do Planejamento, os autores ainda argumentam que a responsabilidade pelas direções está com a alta cúpula e a responsabilidade pelo controle executivo está com os planejadores. Outrossim, as estratégias surgem deste processo por meio de uma atenção detalhada a objetivos explícitos, orçamentos, programas e planos tático-operacionais.

As limitações sob a Escola do Planejamento são resultantes da separação entre planejar e executar e da perspectiva top-down, em que o planeador ao término do planejamento se torna o controlador do que se postulou a ser realizado nos mínimos detalhes. Essa perspectiva é mais afeita a organizações complexas, tais como governos o são, que encontram dificuldades em criar pactuações inter e transetoriais e em avaliar os próprios pressupostos do planejamento numa abordagem de gestão estratégica a partir de orientações gerais mais do que controle rígido de execução.

Em um prisma funcional-organizativo, o planejamento na gestão pública é inserido no conjunto das chamadas áreas-meio das funções de governo, sendo aquelas que dão suporte às áreas finalísticas que são diretamente responsáveis pela execução das políticas públicas. Segundo Soares, "(...) conforme o grau de profundidade e o valor atribuído pelo governo ao planejamento, essa função pode gerar como 
principal produto um documento com uma carta genérica de intenções [ou, num outro extremo, um plano orientador acurado]" (2016: p. 24).

Sob a ótica de uma estratégia governamental meticulosa, Paulo (2010) expõe que o plano personifica político, técnico e metodologicamente o processo de planejamento ao explicitar uma diretriz e uma lógica de encadeamento de atividades. Para Cardoso Junior (2011), o plano parte de um esquema coerente e fundamentado de objetivos que se desdobram em metas quantitativas e qualitativas por meio de ações temáticas e envolvimento de diversos setores que apresentam objetivos, metas e ações escolhidas, a serem implementadas e avaliadas de acordo com certos critérios a serem cumpridos. Assim, no setor público, numa acepção estratégica, um plano é a expressão de dada política, ao determinar qual direcionamento o governo (ou uma organização pública) pretende seguir alicerçado em um conjunto de medidas coordenadas, pactuadas entre instituições e com segmentos da sociedade, e avaliadas constantemente.

\subsection{O Plano Plurianual como Instrumento de Planejamento Governamental}

No planejamento governamental brasileiro pós-redemocratização, ocorreram diversas reformas e inovações nas suas normas e instrumentos, como a lei do plano plurianual (PPA) no Sistema de Planejamento-Orçamento, previsto desde a Constituição Federal de 1988. (Pares \& Valle, 2006).

De acordo com a Carta Magna, em seu artigo 165, a lei do PPA deve estabelecer, de forma regionalizada (neste sentido, com preocupação em programas territorialmente contextualizados e focalizados), as diretrizes, os objetivos e metas da administração pública para as despesas de investimento e outras delas decorrentes e para programas de duração continuada para um período de quatro anos; sua vigência é entre o segundo ano de um mandato até o final do primeiro ano da gestão seguinte, tencionando um ciclo de gestão pública entre dois governos pelo ideário da continuidade administrativa das ações. Em adição, segundo o Art. 48 da Lei Complementar 101 - a Lei de Responsabilidade Fiscal (LRF) -, o PPA deve ser um instrumento de transparência para a gestão fiscal nos quais os resultados do planejamento devem ser divulgados para que suas informações sejam apreciadas pela sociedade.

Sanches (1995) afirma que, ao longo das duas últimas décadas do século XX, a função planejamento adquiriu feições muito diferentes das quais poderia ser portadora no setor público brasileiro. Segundo o autor, tal função se esvaziou de conteúdo político e se tornou robustecida de ingredientes técnicos, de controle e comando físico-financeiros em torno de ações difusas, diluídas pelos diversos níveis e instâncias de governo.

De Toni (2014) reitera que a elaboração dos planos plurianuais, desde 1995, não conseguiu qualificar a agenda estratégica do governo federal, nem alterar a cultura política que orienta a gestão pública na União. Os problemas identificados pela literatura especializada afirmam que ao equiparar as categorias do planejamento com as do orçamento, o PPA tornou-se mais um "orçamento plurianual" no qual a lógica orçamentária de alocação e rigidez, ou dificuldades de se flexibilizar ante novos desafios e oportunidades que surgem, contaminou o desenho de ações e programas. Nas palavras do autor:

"O PPA [no governo federal] tornou-se tão detalhado quanto o próprio orçamento, ao invés de focalizar só ações estruturantes e investimentos. A dimensão tático-operacional sufocou a dimensão estratégica. Como resultado, se tornou prática comum, dada a inadequação dos PPAs como instrumento de gestão estratégica, a elaboração de 'listas de obras prioritárias', com modelos paralelos de gestão (paralelos em relação aos órgãos de planejamento), com ênfase restrita à dimensão orçamentária". (DE TONI, 2014: p. 10, grifo nosso)

No âmbito subnacional, conforme Rocha (2016), a estrutura do PPA tornou-se progressivamente mais robusta, sobretudo nos estados, embora grande parte dos municípios não conceba a formulação do PPA como instrumento de gestão estratégica; isto é, não se trabalha com prioridades claras, formalizadas e atualizadas, assim como não são feitas análises e avaliações das ações governamentais. Mormente, a natureza do plano plurianual nos governos locais é de um documento que cumpre a obrigatoriedade - constitucional - de elaboração, mas desprovido de conteúdo estratégico e mesmo de um teor pertinente à realidade da gestão pública municipal; por vezes, é uma peça de planejamento-orçamento de ficção.

Esse panorama é diametralmente oposto aos ditames de governança pública para os municípios engendrados pelo binômio eficiência-democratização. Consoante Procopiuk et al. (2007): 


\begin{abstract}
"A atuação local requer que algumas premissas fundamentais sejam seguidas, tais como: ações públicas baseadas em processos racionais e coerentes; participação democrática em todas as instâncias e fóruns, com garantia de presença e de voz da sociedade; corpo técnico capacitado; e controle da gestão no que concerne ao acompanhamento das ações públicas. A conjunção dessas premissas na elaboração e na execução dos processos de planejamento e orçamento torna-se cada vez mais importante pelo fato de o desenvolvimento econômico local almejado ser considerado como resultante de esforço cooperativo da municipalidade". (PROCOPIUK et al., 2007, p. 330, grifo nosso)
\end{abstract}

Independente do nível de governo no país, Cardoso Junior (2015, p. 10) afirma que o PPA precisa ser visto e tido como aliado estratégico, e não como "obstáculo constitucional, mal necessário da burocracia ou inimigo público a ser ignorado ou derrotado no campo de batalha da política pública". Ou seja, é mister que os gestores públicos enxerguem o planejamento governamental não como algo utópico, mas sim como função necessária e indelegável do Estado, cada vez mais necessária como parte de uma solução para a complexidade e heterogeneidade das questões sociais e econômicas. E o PPA, como instrumento normativo de planejamento de médio prazo dos governos, tem potencial para um robustecimento macroestratégico.

Findando esta sucinta revisão de literatura, cumpre salientar que nas referências bibliográficas sobre planejamento governamental no Brasil encontram-se variadas análises de Planos Plurianuais do nível federal e, recentemente, do nível estadual. A dissertação de mestrado de Amorim (2016), a título de exemplo, traz um sintético balanço da literatura sobre o PPA na União, enquanto o Instituto de Pesquisa Econômica Aplicada (IPEA) organizou, em 2013, uma coletânea intitulada "Planejamento e Gestão Governamental na Esfera Estadual uma análise comparativa dos processos, conteúdos e sistemas de acompanhamento dos PPAs", na qual esboça uma análise do plano plurianual (2012-2015) de dez estados brasileiros (BA, CE, ES, MG, MS, PR, RN, RS, RJ e SP).

Todavia, a bibliografia sobre PPA nos governos locais ainda é diminuta e se resume a algumas apreciações em eventos de practitioners (sobretudo no Congresso de Gestão Pública CONSAD voltado para boas práticas apresentadas pela burocracia). Em suma, a comunidade acadêmica de planejamento governamental no Brasil mantém a interpretação, que faz jus à realidade, de que o PPA permanece, nas prefeituras, a ser estruturado sob uma perspectiva tão somente técnico-orçamentária, com poucas evidências de seu uso estratégico - técnico e político - na gestão pública municipal.

\title{
2.2 Algumas Informações do Lócus Empírico: Prefeitura Municipal de Osasco-SP
}

Nas próximas seções, como um case contrafactual perante as práticas de planos plurianuais meramente procedimentais nos governos locais, o artigo descreve e analisa o processo de elaboração do PPA (2018-2021) do município de Osasco-SP. Localizado na sub-região Oeste da Região Metropolitana de São Paulo (RMSP), Osasco era um bairro da capital paulista até 1962, ano em que obteve sua emancipação político-administrativa a partir de um plebiscito. Com quase 700.000 habitantes, a cidade é a sétima mais populosa do Estado de São Paulo. Economicamente, segundo o IBGE (2016), o município tem o sexto maior Produto Interno Bruto (PIB) do país e o segundo maior do estado, figurando na frente de muitas capitais brasileiras. Apesar da expressiva atividade industrial, comercial e de serviços, a cidade, como os demais grandes municípios da RMSP, tem enormes contrastes socioeconômicos em seu território e enfrenta desafios complexos e heterogêneos de gestão e políticas públicas.

A Administração Pública Municipal, no quadriênio 2017-2020, é gerida por uma coalizão partidária encabeçada pelo Podemos (antigo Partido Trabalhista Nacional - PTN) e o Partido da República (PR), tendo como prefeito Rogério Lins e como vice-prefeita Ana Maria Rossi. Eleitos em 2016, eles sucederam a gestão do Prefeito Jorge Lapas (2013-2016) - que se elegeu pelo Partido dos Trabalhadores (PT), em 2012, e tentou a reeleição pelo Partido Democrático Trabalhista (PDT), em 2016.

A iniciativa de um PPA Estratégico em Osasco iniciou-se em 2013, no mandato de Lapas, na elaboração do plano plurianual do município para o quadriênio 2014-2017. De acordo com Mancini, Guerra \& Cazzuni (2015):

“Na construção do PPA 2014-2017 [de Osasco], definiram-se 32 objetivos, distribuídos em 11 eixos, nomeados pelas principais áreas de governo, medidos por indicadores com metas anualmente pactuadas e concretizados por meio de iniciativas estratégicas responsáveis por elevar o patamar dos serviços públicos oferecidos e aumentar a qualidade de vida da população". (Mancini, 
Guerra \& Cazzuni, 2015, p. 2, grifo nosso).

Ao assumir o comando da prefeitura municipal em 2017, a gestão Lins manteve uma parcela considerável da equipe de trabalho da SEPLAG e interessou-se pela memória institucional do plano vigente (2014-2017), repetindo a experiência de intentar um PPA com elementos macroestratégicos para o quadriênio 2018-2021 - exposta, a seguir, na seção 3.

\section{Descrição das Etapas de Elaboração do PPA (2018-2021) do Município de Osasco-SP}

O processo de elaboração do Plano Plurianual (2018-2021) do município de Osasco, realizado entre janeiro e julho de 2017, abrangeu oito etapas, especificadas no quadro 1 e relatadas subsequentemente.

Quadro 1 - Elaboração do PPA (2018-2021) de Osasco: etapas, finalidade e produto.

\begin{tabular}{|c|c|c|}
\hline Etapas do Processo & Finalidade da Etapa & Produto Esperado \\
\hline $\begin{array}{l}\text { 1. Encontros intersecre- } \\
\text { tariais de nivelamento }\end{array}$ & $\begin{array}{l}\text { Conscientização dos servidores municipais so- } \\
\text { bre os conceitos do PPA e divulgação das eta- } \\
\text { pas de formulação do plano. }\end{array}$ & $\begin{array}{l}\text { Servidores conscientes sobre como ocorrerá o } \\
\text { processo de elaboração do PPA e qual seu for- } \\
\text { mato e cronograma. }\end{array}$ \\
\hline $\begin{array}{l}\text { 2. Encontro } \\
\text { tariais de } \mathrm{p}\end{array}$ & $\begin{array}{l}\text { Identificação de problemas, causas e estraté- } \\
\text { gias de enfrentamento por eixo temático do } \\
\text { plano do governo. }\end{array}$ & $\begin{array}{l}\text { Materialização da base estratégica do plano de } \\
\text { governo com problemas identificados e priori- } \\
\text { zados. }\end{array}$ \\
\hline $\begin{array}{l}\text { 3. Enc } \\
\text { tariais }\end{array}$ & $\begin{array}{l}\text { Construção dos objetivos estratégicos por eixo } \\
\text { temático. }\end{array}$ & $\begin{array}{l}\text { Definição de dois objetivos estratégicos por } \\
\text { eixo temático, construídos e validados. }\end{array}$ \\
\hline $\begin{array}{l}\text { cretariais } \\
\text { es }\end{array}$ & $\begin{array}{l}\text { Idealização dos indicadores de monitora- } \\
\text { mento e avaliação para cada um dos objetivos } \\
\text { estratégicos. }\end{array}$ & $\begin{array}{l}\text { da cesta de indicadores e das me- } \\
\text { ctuadas. }\end{array}$ \\
\hline $\begin{array}{l}\text { 5. Estimação da receita } \\
\text { pública }\end{array}$ & $\begin{array}{l}\text { Previsão do fluxo de arrecadação própria e das } \\
\text { receitas provenientes das transferências do } \\
\text { governo federal e estadual. }\end{array}$ & $\begin{array}{l}\text { ro-orçamentário para o finan- } \\
\text { A. }\end{array}$ \\
\hline $\begin{array}{l}\text { 5. Encont } \\
\text { ais progr }\end{array}$ & $\begin{array}{l}\text { Desenho em cada secretaria da matriz progra- } \\
\text { mática. }\end{array}$ & $\begin{array}{l}\text { Matriz preenchida com programas e suas ações } \\
\text { (projetos e atividades), indicadores, metas físi- } \\
\text { cas e financeiras. }\end{array}$ \\
\hline $\begin{array}{l}\text { 7. Ajuste das ações à ca- } \\
\text { pacidade do orçamento } \\
\text { municipal }\end{array}$ & $\begin{array}{l}\text { Ajuste discricionário dos programas do PPA à } \\
\text { capacidade do orçamento municipal. }\end{array}$ & Alinhamento entre planejamento e orçamento. \\
\hline $\begin{array}{l}\text { 8. Preenchimento do } \\
\text { PPA no sistema }\end{array}$ & $\begin{array}{l}\text { Preenchimento das informações do PPA no } \\
\text { sistema municipal de planejamento. }\end{array}$ & $\begin{array}{l}\text { PPA cadastrado no sistema e apresentado sob } \\
\text { a forma de Lei. }\end{array}$ \\
\hline
\end{tabular}

Fonte: Elaboração dos autores.

Inicialmente, foram escolhidos o órgão e a equipe responsável para a elaboração do plano que, na Prefeitura Municipal de Osasco, ficou sob a responsabilidade da Secretaria de Planejamento e Gestão (SEPLAG) - tal como na gestão anterior, vide Guerra et al (2016). Assim, a equipe de trabalho, composta por gestores públicos com formação acadêmica em Administração Pública e Economia, decidiu como primeira etapa de tal processo realizar alguns encontros de nivelamento. 0 objetivo era propiciar um entendimento entre os servidores da área de planejamento-orçamento com os servidores públicos das diversas secretarias municipais, convencionando os aspectos normativos do PPA e os elementos estruturais do plano, além do cronograma do trabalho.

Decorrida a primeira etapa, começou-se a prospectar a dimensão estratégica do PPA por meio de documentos de base já existentes no município, tais como: o programa de governo, os planos municipais setoriais vigentes (Educação, Saúde, Mobilidade Urbana, Resíduos Sólidos, dentre outros), os programas governamentais em andamento e as demais políticas públicas originárias de demandas das secretarias e de convênios com os governos federal e estadual.

Em termos metodológicos, primeiramente foram elaborados diagnósticos setoriais para cada um dos 11 eixos estratégicos do programa de governo - enumerados no Quadro 2. A tarefa envolveu uma análise do quadro socioeconômico do município que fez uso tanto de dados secundários como de informações provenientes de pesquisas de opinião que avaliaram a percepção dos munícipes sobre a qualidade dos equipamentos e dos serviços públicos.

Na sequência, com o fito de promover a intersetorialidade, procedeu-se a identificação da matriz de problemas. Para tal, os servidores públicos partiram dos documentos existentes e dos diagnósticos realizados e discutiram as causas, consequências e estratégias de enfrentamento dos problemas, afora 
a ordem de prioridade conforme o nível de importância atribuído pelos técnicos. 0 resultado desses encontros intersecretariais da segunda etapa assinalou um rol de 84 problemas identificados e priorizados por uma vertente mais técnica.

Quadro 2- Eixos Estratégicos do Programa de Governo de Osasco (2018-2021)

\begin{tabular}{|c|l|}
\hline \multicolumn{2}{|l|}{ Eixos Estratégicos } \\
\hline 1 & Saúde \\
\hline 2 & Educação \\
\hline 3 & Segurança e Ordem Urbana \\
\hline 4 & Mobilidade Urbana e Transportes \\
\hline 5 & Zeladoria e Infraestrutura Urbana \\
\hline 6 & Modernização da Gestão, Transparência e Democracia \\
\hline 7 & Habitação \\
\hline 8 & Esporte, Cultura e Lazer \\
\hline 9 & Desenvolvimento Urbano, Econômico-Social e do Trabalho \\
\hline 10 & Meio Ambiente e Sustentabilidade \\
\hline 11 & Assistência e Inclusão Social, Direitos Humanos, Igualdade Racial e de Gêneros \\
\hline
\end{tabular}

Fonte: Secretaria de Planejamento e Gestão da Prefeitura Municipal de Osasco, 2017.

A terceira etapa destinou-se à construção dos objetivos estratégicos a partir dos problemas identificados por eixo temático do programa de governo. Para cada um dos 11 eixos - supracitados no Quadro 2 - foi composto um grupo intersecretarial com os técnicos das pastas responsáveis pelas respectivas temáticas e se estabeleceram, na maioria das vezes, dois objetivos. Como fruto desses encontros da terceira etapa, esboçou-se um Mapa Estratégico formado por 23 objetivos estratégicos para o plano plurianual.

A quarta etapa englobou um conjunto de oficinas para a idealização dos indicadores de monitoramento e avaliação para cada um dos objetivos estratégicos. Em 11 sessões de trabalho com os técnicos das secretarias, definiram-se idealmente dois indicadores por objetivo, apontando para cada indicador sua medição atual, na ocasião, bem como sua meta futura. Observando o PPA (2018-2021) de Osasco, nota-se que a cesta de indicadores é integrada: (a) por indicadores de insumo, por meio da disponibilidade de recursos humanos, financeiros e equipamentos alocados para um programa ou intervenção; (b) por indicadores de processo, como exemplo, a temporalidade da execução da política pública; e (c) por indicadores de produto que representam resultados efetivos das políticas e medidas de condições de vida da população. Segundo Antico \& Jannuzzi (2006), esses indicadores, em um plano plurianual, cumprem com a função de subsidiar o monitoramento e a avaliação dos programas governamentais.

A quinta etapa, destinada à estimação de receitas para o financiamento do PPA, ficou sob a responsabilidade da SEPLAG. Seus técnicos realizaram várias projeções manejando três métodos econométricos: o primeiro fez uma estimação baseada em uma série temporal, o segundo seguiu a metodologia de suavização exponencial com tendência e o terceiro modelo pressupôs o uso da teoria dos mínimos quadrados ordinários. Assim, obteve-se uma previsão multiparamétrica tanto do fluxo de arrecadação própria do município quanto da expectativa de receitas provenientes das transferências repassadas pela União e pelo Estado de São Paulo para a Prefeitura de Osasco. 0 cenário de retração do nível de atividade econômica indicava uma sensível queda no recolhimento dos tributos municipais e nos repasses intergovernamentais, configurando uma conjuntura de aperto fiscal para os anos vindouros.

A sexta etapa, por sua vez, tratou do "Desenho da Matriz Programática", passo de tradução da estratégia governamental para o nível tático-gerencial do PPA - desdobrado em programas governamentais. Para cada problema identificado foi criado determinado programa, e no âmbito de cada programa se propôs um conjunto de projetos/atividades com meta física e financeira para cada um dos quatro anos do plano. Primeiramente, foram selecionados os programas do PPA (2013-2017) a serem replicados no atual e, ulteriormente, foram criados os novos programas.

Esse trabalho serviu-se de ciclos de reuniões com cada pasta da Prefeitura a fim de preencher a matriz programática com as ações (projetos e atividades), metas físicas /financeiras e indicadores para cada um dos programas. O resultado da sexta etapa foi a consolidação das informações/detalhes dos programas, incluindo as classificações orçamentárias que codificam os órgãos/departamentos, programas/ações, funções/subfunções e fontes de recursos.

Com a matriz programática preenchida e consolidada, a sétima etapa objetivou a integração da 
peça de planejamento com a projeção orçamentária do município. Em outras palavras, essa fase buscou uma priorização dos programas, delimitando as ações que comporiam, de fato, o orçamento e o que seria cortado parcial ou integralmente diante da circunstância fiscal desfavorável. O processo decisório ficou a cargo do prefeito, a quem coube definir as preferências de seu governo em conjunto com alguns de seus secretários municipais e sua assessoria. Ocorreram quatro reuniões da equipe de trabalho da SEPLAG com o prefeito e os secretários das áreas-meio da Prefeitura. A participação restrita das áreasmeio, excluindo as pastas finalísticas, foi justificada pelo entendimento de que não era um momento de disputa entre secretarias, mas um instante de priorização baseado no juízo de que "o cobertor é curto" e que, portanto, o processo decisório deveria ser dividido entre o prefeito e o núcleo estratégico de governo.

Após essa escolha/validação do prefeito, procedeu-se a oitava (e última) etapa representada pelo preenchimento das informações do PPA no sistema informatizado de planejamento em meados do mês de julho de 2017. Como desfecho, a elaboração do PPA (2018-2021) de Osasco, iniciada em janeiro e finalizada na última semana de julho, consolidou 37 programas e 148 ações (projetos e atividades) que resultaram em um plano cujo documento tem seis anexos: Guia de Leitura, Diagnóstico Estratégico da Cidade de Osasco, Estimativa da Receita, A Estratégia do PPA, Programas e Ações Governamentais e Estrutura Administrativa. O documento foi encaminhado para revisão da Secretaria de Assuntos Jurídicos e Secretaria de Administração e assinatura do prefeito e, posteriormente, enviado para aprovação da Câmara Municipal no último dia de julho, cumprindo o prazo legal da Lei do PPA.

Para encerrar essa seção, a figura 1 ilustra o processo de elaboração do Plano Plurianual de Osasco para o período 2018-2021, no qual se destacam duas dimensões: a estratégica, realizada entre os meses de janeiro e abril de 2017; e a programática ou tática, realizada entre os meses de abril e julho de 2017. Trata-se de um esquema que lista os macro-estágios trilhados pela prefeitura para intencionar a formulação de um PPA municipal com adensamento estratégico. Como aludido na introdução deste artigo, uma ocorrência atípica nos governos locais brasileiros, ambiência na qual predominam os PPAs de Gabinete e Encomendado.

Figura 1 - Fluxo de Elaboração do PPA (2018-2021) de Osasco - jan.-jul. de 2017.

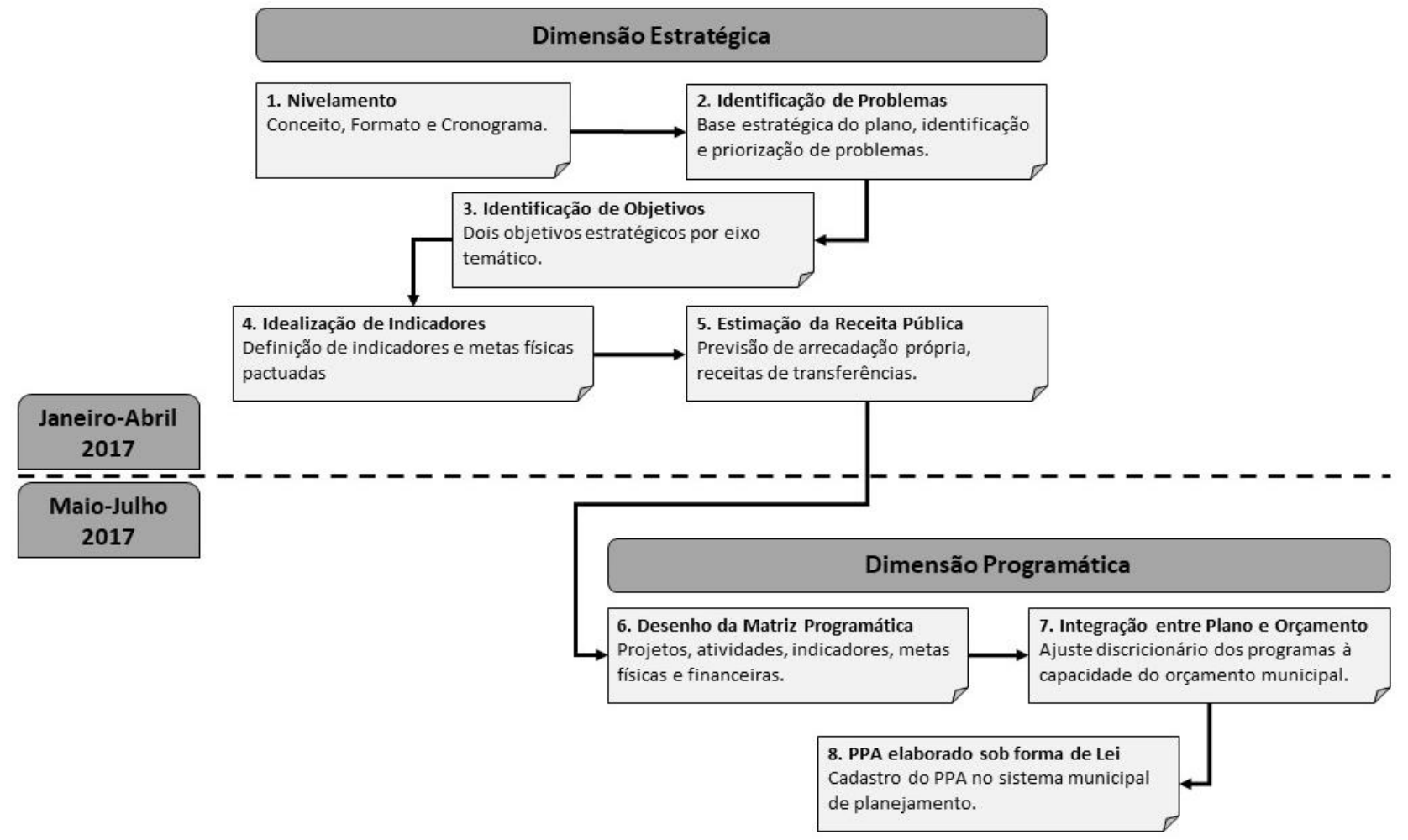

\section{Fonte: Elaboração dos Autores.}

A seguir, a seção 4 averigua o quão estratégico foi o processo de elaboração desse plano plurianual de Osasco sob a lente analítica do conceito de densidade macroestratégica. 


\section{Plano Plurianual de Osasco (2018-2021): uma análise da densidade macroestratégica}

Como apontado sucintamente na introdução, o conceito de densidade macroestratégica possibilita analisar alguns atributos nas formulações dos PPAs municipais a partir de algumas variáveis político-administrativas que interpenetram aspectos técnicos de processos e fluxos de trabalho com aspectos políticos do planejamento governamental no poder local. Das sete variáveis que perfazem o constructo de densidade macroestratégica - segundo Olenscki et al (2017) -, identificamos cinco na análise do processo de elaboração do plano plurianual de Osasco (2018-2021), conforme indica o quadro 3. Quadro 3 - Identificação das Variáveis de Densidade Macroestratégica no Processo de Elaboração do PPA (2018-2021) de Osasco

\begin{tabular}{|l|c|}
\hline \multicolumn{1}{|c|}{ Variáveis Político-Administrativas de Densidade Macroestratégica } & Plano Plurianual (2018-2021) \\
\hline Ação/Nuance de governo & Não identificada* \\
\hline Liderança (s) institucional (is) e memória institucional & Identificada \\
\hline Participação social e permeabilidade organizacional aos cidadãos & Não identificada \\
\hline Ciclo político-eleitoral & Identificado \\
\hline Mensuração de necessidades e recursos & Identificada \\
\hline Alternativas de recursos financeiros & Identificada \\
\hline Mecanismos de gestão tático-operacional e de projetos & Identificada \\
\hline
\end{tabular}

Fonte: Elaboração dos Autores. * Não se aplica à formulação do PPA, mas à implementação do plano.

A primeira variável de densidade macroestratégica se manifesta pela ideia de "ação/nuance de governo". Neste caso, investiga-se como o chefe do Poder Executivo municipal interfere, altera, reconstrói o processo de planejamento-orçamento no decorrer do mandato. Como essa variável diz respeito à implementação do PPA durante a vigência do plano, não foi possível fazer uma análise neste artigo, haja vista o enfoque do trabalho no ciclo de formulação do instrumento.

A segunda variável consiste nas noções de "liderança(s) institucional(is) e memória institucional", para as quais se tem o pressuposto de que há uma organização central formuladora do PPA e se investiga qual o grau de empoderamento da atividade de planejamento estratégico associada com a capacidade de liderança de tal organização em se articular com o prefeito, além da existência de memória institucional para subsidiar a construção do plano. A SEPLAG, como órgão central de articulação do PPA, exerceu o papel de orientar e sistematizar o processo, além de manter seus quadros técnicos mesmo com a alternância de poder nas eleições de 2016. Essa permanência da equipe de trabalho contribuiu para a memória institucional em termos de know-how para a elaboração do plano e aproveitamento das ações/práticas exitosas da gestão anterior.

A terceira variável diz respeito ao nível de "participação social e permeabilidade organizacional aos cidadãos", relacionando a formulação do PPA aos princípios de accountability, transparência ativa e mobilização efetiva da sociedade civil na construção e no controle do planejamento. Tal variável não foi identificada no processo de elaboração do PPA (2018-2021) de Osasco, visto que a metodologia escolhida pelo alto escalão da SEPLAG não previa etapas participativas na estruturação do plano, a não ser a audiência pública do Projeto de Lei do PPA na Câmara Municipal. Contudo, pode-se afirmar que nos contornos da prefeitura municipal houve uma participação ampla do corpo técnico-administrativo, com o envolvimento dos diferentes níveis da burocracia municipal do alto e médio escalão, assim como de alguns burocratas operacionais e do nível de rua. Ainda que essa ocorrência não ratifique a variável em análise, trata-se de um fato digno de nota.

A quarta variável considera o "ciclo político-eleitoral", assimilado como o período do mandato no qual vigora uma percepção positiva do eleitorado quando o prefeito apresenta projetos visíveis e de fácil aceitação/aprovação popular. O PPA (2018-2021) da Prefeitura Municipal de Osasco, ao tomar como base os programas da gestão passada, consubstanciou um grau de continuidade programática. Todavia, o novo mandatário foi perspicaz ao compreender a não reeleição de seu concorrente e a necessidade de propor alguns novos projetos e circunscrever sua marca de governo. Nessa direção, na etapa política de priorização das ações governamentais do PPA, o prefeito recém-eleito optou por algumas atividades no curto prazo de recapeamento asfáltico e construção de novos equipamentos públicos municipais na área de esporte e lazer. 
Como quinta variável encontra-se a "mensuração de necessidades e recursos", na qual se reflete sobre o grau de associação entre uma pertinente formulação de estratégias no PPA com um factível provimento de recursos para a concretização do plano. Essa variável está ligada à prática de elaboração de diagnósticos com a valorização de juízos tecnopolíticos que busquem dar conta da complexidade de problemas e ao nível de refinamento e detalhamento dos recursos necessários e possíveis para sua solução. No plano plurianual (2018-2021) Osasco, os elementos dessa variável se fizeram presentes agregadamente - nas etapas de identificação de problemas, construção dos objetivos estratégicos, estimação da receita e ajuste das ações governamentais à capacidade orçamentária do município.

A sexta variável de densidade macroestratégica fixa-se nas "alternativas de recursos financeiros", isto é, como se rastreia no processo de elaboração do PPA as alternativas de financiamento das ações governamentais dentro dos cânones do planejamento programático e de uma visão estratégica da alocação de recursos durante o ciclo orçamentário do plano. No caso de Osasco, a SEPLAG, em diálogo constante com as outras pastas da prefeitura, articulou e incentivou a concepção de programas/projetos com orçamento vinculado em fontes de recursos dos demais entes federativos, seja na forma de transferências intergovernamentais voluntárias (convênios e contratos de repasse), seja na forma de exequíveis operações creditícias, empenhando-se para viabilizar, financeiramente, a consecução do plano.

Por fim, a sétima variável, alusiva aos "mecanismos de gestão tático-operacional e de projetos", focaliza - no estágio de formulação do plano plurianual - a utilização de múltiplas metodologias de elaboração/design de programas. Neste sentido, se investiga o alinhamento entre a orientação estratégica do governo e as ações governamentais do PPA, e a coerência e consistência dos projetos e atividades. A formulação do PPA (2018-2021) de Osasco, pautada pela aplicação de métodos e técnicas de planejamento governamental, evidencia essa tradução da dimensão estratégica do plano na sua matriz programática.

Em conclusão, esta análise do processo de elaboração do PPA (2018-2021) de Osasco, ainda que concisa, identifica nesse instrumento de planejamento governamental, uma vez cotejado com as variáveis político-administrativas de densidade macroestratégica, cinco das sete variáveis. Tal indício assinala, de maneira exploratória, a caracterização de um PPA Estratégico municipal - fenômeno empírico raro nesses 30 anos de uso compulsório do instrumento e prática de gestão pública bastante incomum nos governos locais do Brasil.

\section{Considerações finais}

A Secretaria de Planejamento e Gestão (SEPLAG), da Prefeitura Municipal de Osasco, após o êxito do Plano Plurianual (2014-2017), foi designada - novamente - para o processo de elaboração do PPA (2018-2021) com a subsistência de sua equipe de trabalho nos cargos em comissão e funções de confiança, mesmo com a alternância de poder no município. Aproveitando-se do instrumento anterior, o plano atual organizou-se em oito etapas (baseadas em reuniões secretariais e intersecretariais) realizadas entre janeiro e julho de 2017, para formular as diretrizes e ações governamentais integradas ao orçamento.

Neste artigo, ao descrever o processo de elaboração desse planejamento governamental de Osasco e analisar sua densidade macroestratégica, pode-se afirmar que o plano tem indícios de um PPA Estratégico, o que é atípico nos governos locais do país que tratam, comumente, sua obrigatoriedade como um dispositivo formal desimportante ou um reles aparato ficcional - longínquo de uma ferramenta gerencial de gestão pública municipal.

A análise da elaboração do Plano Plurianual de Osasco (2018-2021) considerou o PPA não como uma peça, mas como um instrumento que está imerso em um contexto político e técnico de conflitos e cooperações, bem como de análises e escolhas. 0 conceito de densidade macroestratégica, sugestionado por Olenscki et al (2017), fundamentou tal análise a partir de variáveis político-administrativas: ação/nuance de governo; liderança(s) institucional(is) e memória institucional; ciclo político-eleitoral, participação social e permeabilidade organizacional, mensuração de necessidades e recursos; alternativas de recursos financeiros e mecanismos de gestão tático-operacional. Dessas sete variáveis, cinco foram identificadas nas etapas de formulação do PPA municipal.

Em adição, a estrutura do referido plano demandou que sua construção fosse efetuada na forma de teia, visto que o instrumento pretendeu coadunar articulações intersetoriais com um compromisso 
macrogovernamental. Esse é um modelo pouco usual e muito desafiador de PPA, já que existe uma dificuldade de alinhamento administrativo entre as secretarias diante de uma natural disputa política pela liderança de projetos e recursos no município. E ao planear esse caráter de transversalidade e com o envolvimento de diferentes escalões da burocracia local, a elaboração do Plano Plurianual de Osasco (2018-2021) acarretou um efeito de aprendizagem organizacional: os servidores públicos que participaram ativamente do processo difundiram as concepções gerenciais do instrumento para outras atividades nas diferentes pastas da prefeitura.

Entre as limitações do trabalho, incumbe frisar a realização de uma análise do PPA sem uma gradação minuciosa para a identificação das variáveis de densidade macroestratégica. No âmbito deste artigo optou-se por examinar o Plano Plurianual de Osasco (2018-2021) a partir de uma categorização binária - "identificado" e "não identificado" -, mais consentânea com os objetivos de uma observação de cunho exploratório. Investigações futuras têm a oportunidade de avançar com a proposição de um modelo analítico com níveis de reconhecimento/atendimento de cada uma das variáveis político-administrativas. Ademais, as entrevistas semiestruturadas com informantes-chave não foram utilizadas - textualmente - no artigo como citação direta. 0 uso delas, nesta investigação, foi para a checagem dos dados advindos da análise documental e da observação participante.

Em termos de uma agenda de pesquisa mais ampla, uma lacuna que se manifesta é a realização de estudos relativos à implementação do PPA, além de sua formulação. Pode-se ter um plano - no papel que se atente às complexidades setoriais e intersetoriais; ao nexo entre aspectos técnicos e políticos; e ao estabelecimento pormenorizado de recursos a serem alocados por programa, com as metas físicas e financeiras para as ações governamentais. Contudo, é admissível que o conjunto de programas (com seus projetos/atividades) não represente o que se realiza a posteriori, em meio à inexistência de uma gestão estratégica do plano durante a sua vigência ou mesmo diante de dinâmicas políticas ou constrangimentos fiscais inerentes à Administração Pública, de modo a se produzirem novas demandas ou necessidades de ajustes.

Espera-se que, nos anos vindouros, o fenômeno de "PPAs Estratégicos" nos municípios seja mais propagado na literatura nacional de planejamento governamental, retratando boas práticas equivalentes ou similares ao caso de Osasco, descrito e analisado neste artigo. Para além da averiguação nas capitais dos estados brasileiros, é bem-vindo um recorte em prefeituras de cidades de grande e médio porte do interior que tenham sinais de capacidade estatal mobilizada em prol da planificação e do orçamento públicos.

\section{Referências}

Amorim, I. T. (2016). A Institucionalização do Plano Plurianual (PPA): um estudo no governo federal brasileiro nos períodos 2000-2003 e 2004-2007. (Dissertação de mestrado, Universidade de São Paulo, São Paulo, SP).

Antico, C.; e Jannuzzi, P. de M. (2006). Indicadores e a Gestão de Políticas Públicas. São Paulo: Fundap.

Azevedo, R. R., \& Aquino, A. C. B. (2016). 0 planejamento em municípios de pequeno porte em São Paulo. Revista de Contabilidade e Organizações, 10 (26), 63-76.

Brasil. (1988). Constituição da República Federativa do Brasil de 1988.

Brasil. (2000). Lei Complementar no ${ }^{\circ}$ 101, de 4 de maio de 2000. Dispõe sobre a Lei de Responsabilidade Fiscal.

Cardoso Jr., J. C. (2011). Planejamento governamental e gestão pública no Brasil: elementos para ressignificar o debate e capacitar o estado. Brasília: Ipea (Texto para Discussão, n. 1584).

Cardoso Jr., J. C. (org.) (2015). Planejamento Brasil Século XXI: inovação institucional e refundação administrativa - elementos para o pensar e o agir. Brasília: Ipea.

Carrol, L. (2005). Alice no País das Maravilhas. São Paulo: Nobel.

De Toni, J. (2014). A retomada do planejamento governamental: novos dilemas e perspectivas. Revista Brasileira de Planejamento e Orçamento, 4 (1), 4-20.

Ezpeleta, J., \& Rockwell, E. (1986). Pesquisa participante. São Paulo: Cortez.

Guerra, A. L., Cazzuni, D. H., Coelho, R. P. S., \& Reinach, S. (orgs.). (2016). Planejamento público e gestão por resultados: uma experiência municipal aplicada. São Paulo: Hucitec.

Instituto de Pesquisa Econômica Aplicada. (2013). Planejamento e Gestão Governamental na Esfera Es- 
tadual uma análise comparativa dos processos, conteúdos e sistemas de acompanhamento dos PPAs. Brasília: IPEA (relatório de pesquisa consolidado). Recuperado de: http://www.ipea.gov.br/redeipea/images/pdfs/termo_referencia/relatorio_pesquisa_relatorio_consolidado.pdf

Maciel, E. (1989). A crise do planejamento brasileiro. Revista do Serviço Público, 177 (1), 37-48.

Mancini, B., Guerra, A., \& Cazzuni, D. H. (2015). Gestão orientada para resultados em Osasco-SP: da vinculação do orçamento à estratégica ao monitoramento e avaliação dos resultados. Anais Eletrônicos do $X$ Congresso Consad de Gestão Pública. Brasília: Conselho Nacional dos Secretários de Estado de Administração.

Matus, C. (2006). 0 plano como aposta. In: Pagnussat, J. L., Giacomoni, J. (org). Planejamento e Orçamento Governamental. Coletânea, vol. 1. Brasília: Enap.

Mintzberg, H., Ahlstrand, B., \& Lampel, J. (2010). Safari de Estratégia: um roteiro pela selva do planejamento estratégico. São Paulo: Bookman.

Ortiz, M. S. P., \& Medeiros, A. K. (2017). Reforma Gerencial em Contexto Local: Estudo Comparado dos Municípios de Osasco e Niterói. Administração Pública e Gestão Social, 9 (3), 227-236.

Olenscki, A. R. B., Coelho, F. S., Pires, V. A., Terence, A. C. F., \& Peres, U. D. (2017). Densidade Macroestratégica na Gestão Pública Municipal no Brasil: Uma Abordagem analítico-metodológica de PPAs e de variáveis político-administrativas. RACE: Revista de Administração, Contabilidade e Economia, 16(3), 911-932.

Osasco. (2017). Prefeitura Municipal de Osasco: Construção da Base Estratégica para o PPA 2018-2021. Documento da SEPLAG, mimeo.

Osasco. (2017). Lei $n^{\circ} 4851$, de 4 dezembro 2017. Dispõe sobre o Plano Plurianual do Município de Osasco para o quadriênio 2018-2021. Recuperado de: https://leismunicipais.com.br/a/sp/o/osasco/lei-ordinaria/2017/486/4851/lei-ordinaria-n-4851-2017-dispoe-sobre-o-plano-plurianual-do-municipio-de-osasco-para-o-quadrienio-compreendido-entre-2018-a2021

Papi, L. P., \& Demarco, D. J. (2018) Planejamento Governamental nos Municípios Brasileiros: um debate sobre a construção das Capacidades Estatais no Rio Grande do Sul. Anais Eletrônicos do XI Encontro da $A B C P$. Curitiba: Associação Brasileira de Ciência Política.

Pares, A., \& Valle, B. (2006). A retomada do planejamento governamental no Brasil e seus desafios. In: Pagnussat, J. L., Giacomoni, J. (orgs). Planejamento e Orçamento Governamental. Coletânea, vol. 1. Brasília: Enap.

Paulo, L. F. A. (2010) O PPA como instrumento de planejamento e gestão estratégica. Revista do Serviço Público, 61 (2), 171-187.

Procopiuk, M., Machado, E. T., Rezende, D. A., \& BESSA, F. L. B. (2007). O Plano Plurianual Municipal no sistema de planejamento e orçamento brasileiro. Revista do Serviço Público, 58 (4), 397-415.

Rocha, M. (2016). Arranjos institucionais e planejamento público: análise a partir dos planos plurianuais (1991-2005). Teoria \& Pesquisa: Revista de Ciência Política, 25 (1), 120-152.

Sanches, O. M. (1995). Processo orçamentário federal: Problemas, causas e indicativos. Revista de Administração Pública, 29 (3), 122-156.

Silva, N. S. (2017). A Institucionalização do Planejamento Público Orçamentário: uma análise dos Municípios do Piemonte Norte do Itapicuru/BA, entre os anos de 2004 e 2015. (Dissertação de mestrado, Universidade de Salvador, Salvador, BA).

Silva, R. B. P. (2018). Planejamento governamental com densidade macroestratégica em municípios: um estudo multicaso sobre o Plano Plurianual de Niterói-RJ e Osasco-SP. (Dissertação de mestrado, Universidade de São Paulo, São Paulo, SP).

Soares, C. M. (2016). A ressignificação do planejamento público a partir da participação social -Estudo de caso do PPA Participativo da Bahia. (Dissertação de mestrado, Escola de Governo da Fundação João Pinheiro, Belo Horizonte, MG). 